Chimia 46 (1992) 141-148

(c) Schweiz. Chemiker-Verband; ISSN 0009-4293

\section{Quantitative Capillary Supercri- tical Fluid Chromatography and Supercritical Fluid Extraction of Basic Drugs of Abuse}

\author{
Patrick Edder $\left.{ }^{\mathrm{a}}\right)^{*}$, Werner Haerdi $^{\mathrm{a}}$ ), Jean-Luc Veuthey ${ }^{\mathrm{a}}$ ), and Christian Staub ${ }^{\mathrm{b}}$ )
}

\begin{abstract}
Capillary SFC of basic drugs of abuse have been studied using two different columns, and the results were compared with GC. These results have proved the ability of supercritical $\mathrm{CO}_{2}$ to solubilize and extract basic drugs of interest. A novel restrictor has been used to control precisely the flow rate through the extraction cell over a long period of time. Optimal conditions for quantitative recoveries of aqueous morphine adsorbated on C18 silica by SFE has been determined. Recoveries of $100 \%$ with a variation of $2 \%$ was obtained with an extraction time of $25 \mathrm{~min}$. The influence of the pressure, solvent modifier, and flow rate of extraction fluid on the extraction efficiency was determined. These conditions were also found to be applicable for extracting other drugs of abuse.
\end{abstract}

\section{Introduction}

Recently, there has been a growing interest in supercritical fluid extraction (SFE), because it offers several advantages over other extraction techniques used for isolating analytes from environmental and complex biological solid matrices [13]. One of the attractive features of SFE is that it is possible to directly couple the SFE step with chromatographic techniques. This then allows off-line or online determination of compounds of interest and enables to increase the sensitivity and the degree of automation of the method [4][5].

The extraction of basic drugs of abuse from physiological fluids, organs, or even hairs remains still a problem in clinical or forensic laboratories. For instance, extraction of morphine alkaloids, which are basic drugs, are tedious and time-consuming procedures, involving losses or con-

\footnotetext{
${ }^{*}$ Correspondence: P. Edder ${ }^{a}$

a) Department of Mineral, Analytical and Applied Chemistry

University of Geneva, Sciences II

30, quai Ernest-Ansermet

$\mathrm{CH}-1211$ Genève 4

b) Institute of Forensic Medicine of Geneva 9, Avenue de Champel, C.M.U. $\mathrm{CH}-1211$ Genève 4
}

taminations and are not amenable for automatic analyses. Basic drugs of abuse are generally extracted from biological solid matrices by liquid-solid extraction (e.g. Soxhlet). The clean-up step which follows is long and is carried out by extraction on silica cartridges (solid-phase extraction: SPE) [6]. The extraction efficiency is rather poor. However, for physiological fluids (blood, urine), the silica cartridge procedure works well and is routinely used. A limitation of this method is that direct coupling of SPE with chromatographic techniques other than HPLC is very difficult. In contrast, SFE could be a suitable technique for extraction of basic drugs of abuse from biological matrices as well as for direct coupling with chromatographic techniques. To date, only few studies have been reported on the quantitative SFE from complex biological matrix [7].

Extraction of basic drugs of abuse from complex biological matrices requires a knowledge of their solubilities and their behavior in supercritical fluids, particularly $\mathrm{CO}_{2}$. Thus, the solubilization of polar solutes in supercritical fluids remains a challenging task. In 1977 Stahl laid down some rules for predicting the solubilities of polar molecules in $\mathrm{CO}_{2}$ [8]. The basic drugs of abuse either contain tertiary amino groups (e.g. morphine, cocaine, methadone, diazepam) or secondary amino groups (e.g. amphetamines and some benzodiazepines). We have focussed our attention on the extraction of the former. In addition to the amino groups, some of these alkaloids have one or more $\mathrm{OH}$ groups (codeine, morphine) making them more polar. A literature survey showed that tertiary amines are soluble in $\mathrm{CO}_{2}$ without solvent modifiers and can be analyzed by capillary supercritical fluid chromatography (SFC) [9-11]. A study of the effect of $\mathrm{OH}$ groups on the separation of polyglycerol esters indicated that compounds possessing less than four $\mathrm{OH}$ groups are soluble in $\mathrm{CO}_{2}$ [12].

On the other hand Janicot et al. [13] have reported that large amounts of modifier $\left(\mathrm{MeOH} / \mathrm{H}_{2} \mathrm{O} / \mathrm{Et}_{3} \mathrm{~N}\right)$ have to be added to $\mathrm{CO}_{2}(15-20 \%)$ for obtaining a good separation of morphinic alkaloids by packed SFC, the interaction between these compounds and the bare or modified silica being very strong. Other studies on the analyses of basic drugs such as amphetamines [14], benzodiazepines [15], barbiturates [16], $\beta$-blockers [17], cocaine, and codeine [18] by packed column SFC have also been done.

As indicated by several workers, the retention of polar compounds on packed column SFC is principally due to the interactions between the solutes and the stationary phase through the silanol groups. Adding a polar modifier to the $\mathrm{CO}_{2}$ affects and minimizes these interactions to a greater extent than the solubility of the solutes [19][20].

Based on the previous results, we have chosen capillary column SFC for understanding the behavior of the polar analytes in supercritical $\mathrm{CO}_{2}$. Although capillary SFC has been employed for the analyses of drugs of abuse [21-25], there is a dearth of information regarding quantitative determination using either packed or capillary column SFC (note that Karlsson et al. have done quantitative work with solutes of various polarity [26]). This shows the infancy of the SFC technique.

The aim of this work is to develop a SFE procedure for quantitative recovery of diverse drugs e.g. morphine, cocaine, from complex biological matrices such as liver, kidney, brain, hairs, urine, and blood. In the last two samples, extraction of these drugs were carried out after adsorption onto a solid support. But before applying SFE to these matrices, solubilities of basic drugs in $\mathrm{CO}_{2}$ with capillary SFC must be studied. However, after achieving our primary goal, quantitative capillary SFC of basic drugs of abuse was performed to investigate the potential use of this technique compared with $\mathrm{GC}$ analysis. But, as the ultimate goal is to couple SFE directly with chromatographic techniques, deriva- 
tization of the drugs of interest was avoided.

Preliminary studies with SFC showed that, although analysis by SFC cannot compete with $\mathrm{GC}$, it indicated that $\mathrm{CO}_{2}$ without any modifier is able to solubilize basic drugs of abuse. Hence, a detailed SFE study of morphine was performed, as it is one of the most difficult one to extract due to its stronger polarity.

Like in the case of packed SFC, SFE of morphinic alkaloids in poppy straw studies showed that high proportions of polar modifier in $\mathrm{CO}_{2}$ are necessary to extract these compounds quantitatively [27]. This suggests stronger extracting capacity is required due to matrix effects. For these reasons, to determine the optimal SFE conditions for morphine extraction (mobile phase, pressure, temperature, period, flow rate), a matrix effect was simulated by extracting morphine first adsorbed on to a solid support to represent more real conditions.

\section{Experimental}

\subsection{Material}

$99.99 \% \mathrm{CO}_{2}$ purity was purchased from $A G A$ (Geneva, Switzerland). A charcoal-packed column was incorporated prior to the pump to prevent eventual sample contamination by hydrocarbons.

HPLC grade quality $\mathrm{MeOH}$ (99.9\% purity) was purchased from Maechler $A G$ (Basel, Switzerland). $\mathrm{Et}, \mathrm{N}$ ( $99.5 \%$ purity) was obtained from Fluka (Buchs, Switzerland).

Silica C18 was purchased from MachereyNagel (Duren, Deutschland). Amino, cyano, diol and pure silica were obatined from Waters (Milford, Massachussetts, USA). Phenyl silica was obtained from Analytichem International (Harbor City, USA).

Morphine, codeine, methadone, papaverine were obtained from Siegfried $A G$ (Zofingen, Switzerland). Diazepam, imipramine, cocaine, benzoylecgonine, and strychnine were given as gifts by the Institute of Forensic Medicine of Geneva.

\subsection{Apparatus}

2.2.1. Supercritical Fluid Chromatography. A Carlo-Erba SFC3000 chromatograph (purchased from Brechbiihler S.A. Geneva, Switzerland) was used for analysis of samples by SFC.

$200 \mathrm{nl}$ of sample were introduced via splitless injection using pneumatically actuated valve. The injection time was optimized at $2 \mathrm{~s}$. Carbon dioxide was used as the mobile phase. Two types of capillary SFC columns (differing in their polarities) were used:

- DB5, $20 \mathrm{~m} \times 0.1 \mathrm{~mm}$ i.d., film thickness 0.4 $\mu \mathrm{m}$ ( $J \& W$ Scientifics, Folsom, USA).

- DBWAX, $20 \mathrm{~m} \times 0.1 \mathrm{~mm}$ i.d., film thickness $0.1 \mu \mathrm{m}$ (J\&W Scientifics, Folsom, USA).

The chromatographic system was equipped with a Flame Ionization Detector (FID). The detector temp. was $300^{\circ}$. The following FID settings were used: $\mathrm{H}_{2}$ flow rate $=30 \mathrm{ml} / \mathrm{min}$; air flow $=300 \mathrm{ml} / \mathrm{min} ;$ and $\mathrm{N}_{2}$ (as the detector makeup gas) with flow rate $=30 \mathrm{ml} / \mathrm{min}$.

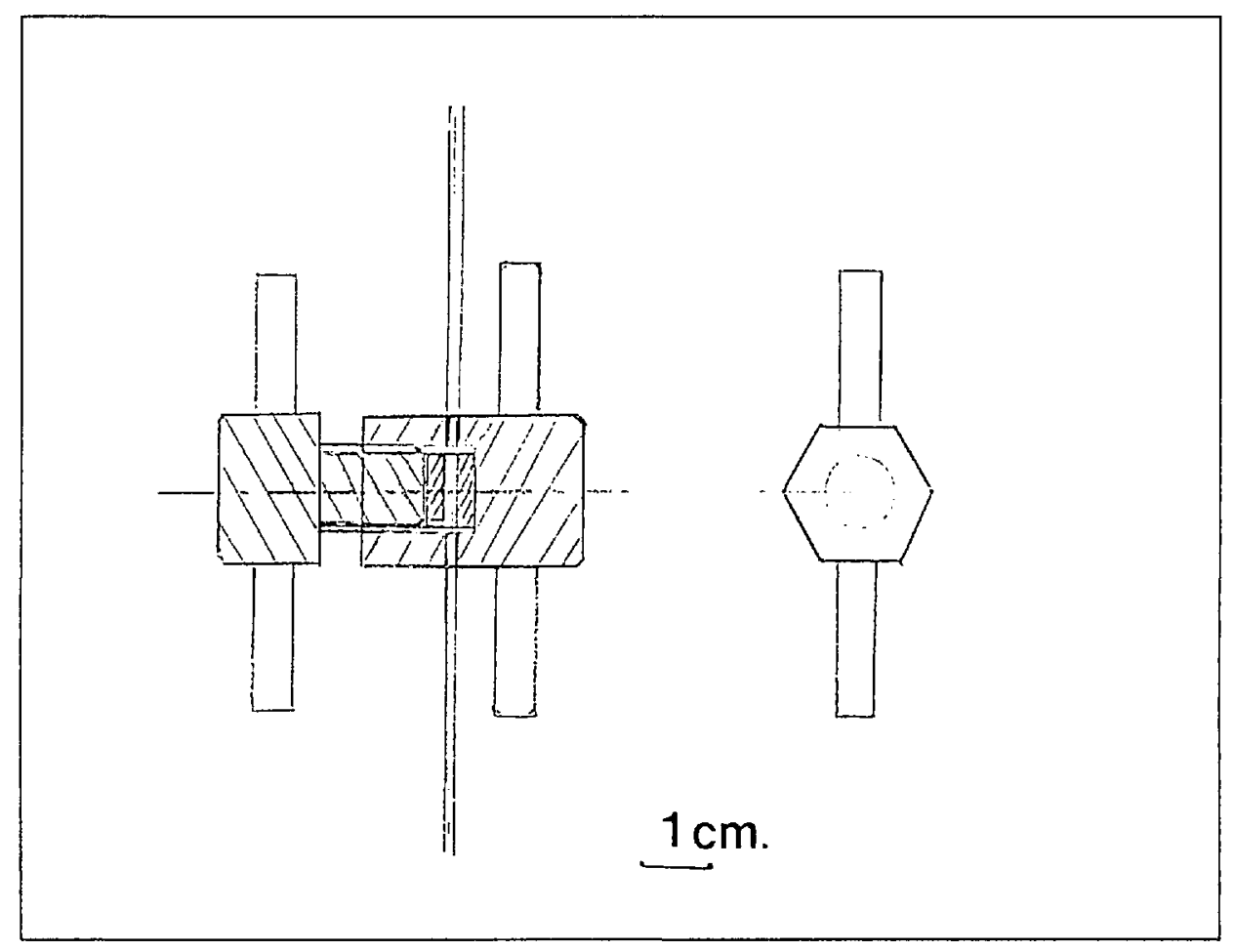

Fig. 1. A schematic diagram of the SFE restrictor

A tapered fused silica tube of $100 \mu m$ i.d. was used as the restrictor. This restrictor has an integrated restriction of $8 \mathrm{ml} / \mathrm{min}$ (this value corresponds to a flow of $8 \mathrm{ml} / \mathrm{min}$ of $\mathrm{CO}_{2}$ under normal pressure at the end of the cap. and under initial column-pressure/temperature conditions of 100 bar $/ 30^{\circ}$ ). A HP3392 integrator (Hewlett-Packard, Palo Alto, USA) was used for integrating the signals.

For comparison, samples were also analyzed by using an HP5890 gas chromatograph (HewlettPackard, Palo Alto, USA) with on-column injection and an FID detector. Same FID gas setting as SFC was used.

He was used as the carrier gas with a flow rate of $1.1 \mathrm{ml} / \mathrm{min}$. The volume of sample injected was $1 \mu \mathrm{l}$. A $1 \mathrm{~m} \times 0.32 \mathrm{~mm}$ i.d. deactivated capillary fused silica column was connected to a $20 \mathrm{~m} \times 0.32 \mathrm{~mm}$ i.d. capillary column of $S E-54$, film thickness of $0.53 \mathrm{um}$ (Hewlett-Packard, Palo Alto, USA) using a glass presfit connector to avoid column contaminations.

2.2.2. Loading Step. As mentioned earlier, optimal conditions for extracting morphine by SFE were determined by adsorbing it onto a solid support. A solid support was used to introduce matrix effect. This would then be representative of conditions encountered in real systems.

The loading was done directly in the extraction cell (cell capacity: $720 \mu$; dimension: $7.5 \mathrm{~cm}$ $\times 3.5 \mathrm{~mm}$ i.d.). Solns. were pumped by a HPLC pump SSI 300 LC (State College, USA) to the extraction cell at a flow rate of $1 \mathrm{ml} / \mathrm{min}$. The cell was packed with the support used for loading the sample. The supports were first washed with 10 $\mathrm{ml}$ of $\mathrm{MeOH}$ and then with $20 \mathrm{ml}$ of $\mathrm{H}_{2} \mathrm{O}$ prior to the percolation. A HP 1040A diode array UV/ VIS detector (Hewlett-Packard, Palo Alto, USA) was used to monitor the eluted morphine. Various supports were tested to select the best support for loading alkaloids drugs. In addition, for applying SFE to the analysis of basics drugs of physiological fluids, attempts were made to preconcentrate large volumes of urine or blood to choose the best support.
2.2.3. Supercritical Fluid Extraction. The SFE apparatus was constructed in-house. CarloErba SFC 300 syringe pumps were used to deliver $\mathrm{CO}_{2}$ and the modifier. The two solvents were mixed in a column held at $40^{\circ}$.

A six-way valco valve was used to by-pass the extraction cell which was placed in a oven held at $40^{\circ}$.

A block heater at $100^{\circ}$ was used for heating the restrictor in order to avoid dry ice formation due to the decompression of the $\mathrm{CO}_{2}$

Extraction pressure and flow rate could not be controlled well due to clogging of the restrictor by dry ice formation or by precipitates of the extracted solutes. This then significantly affects the extraction efficiency. Consequently, it is absolutly essential to be able to vary the restrictor outlet during the extraction in order to maintain the same conditions throughout the extraction period and to improve the reproducibilities of different SFE procedures. The disadvantage of using a fused silica capillary as restrictor is that it has to be changed: $i$ ) if it is plugged; ii) if the restrictor conditions (e.g. higher flow rate at the same pressure) have to be varied.

With a stainless-steel-stressed restrictor, it was possible to regulate the flow at constant pressure, but its limitation is that it has to be taken out of the collection vessel for modifying the end of the tubing with a nippers, this results in poor recoveries and reproducibilities.

To overcome these problems a new restriction system was designed. This restrictor allows to regulate the extraction flow rate with precision at constant pressure during the extraction period without the need to remove the collection vessel A schematic diagram of the restriction system is shown in Fig. $l$.

PEEK tubing of 0.005 inch i.d. (purchased by Upchurch Scientific, Oak Harbor, USA) was used as the restrictor. It was pressed between two disks of $1-\mathrm{cm}$ diameter and tightened by means of a screw. The advantage of the PEEK tubing is that it regains its original form even after being strongly pressed between the disks. If the restrictor gets clogged, it is sufficient to slightly loosen the 
screw to unplug the restrictor and regulate the flow (at constant pressure) again by tightening the screw. Thus, the collection vessel need not be removed during unplugging of the restrictor. The end of the PEEK restrictor was immerged in $\mathrm{MeOH}$ and the solvent vapors due to aerosol formation were recondensed by a cooling circuit situated above the vessel.

\section{Results and Discussions}

\subsection{Capillary Supercritical Fluid Chro- matography}

The use of capillary SFC was two folds. Firstly, to determine the solubilities of basic drugs in $\mathrm{CO}_{2}$ for further applications of SFE. Secondly, to obtain quantitative results for evaluating the performance of capillay SFC as an analytical tool for drugs of abuse in forensic sciences. The
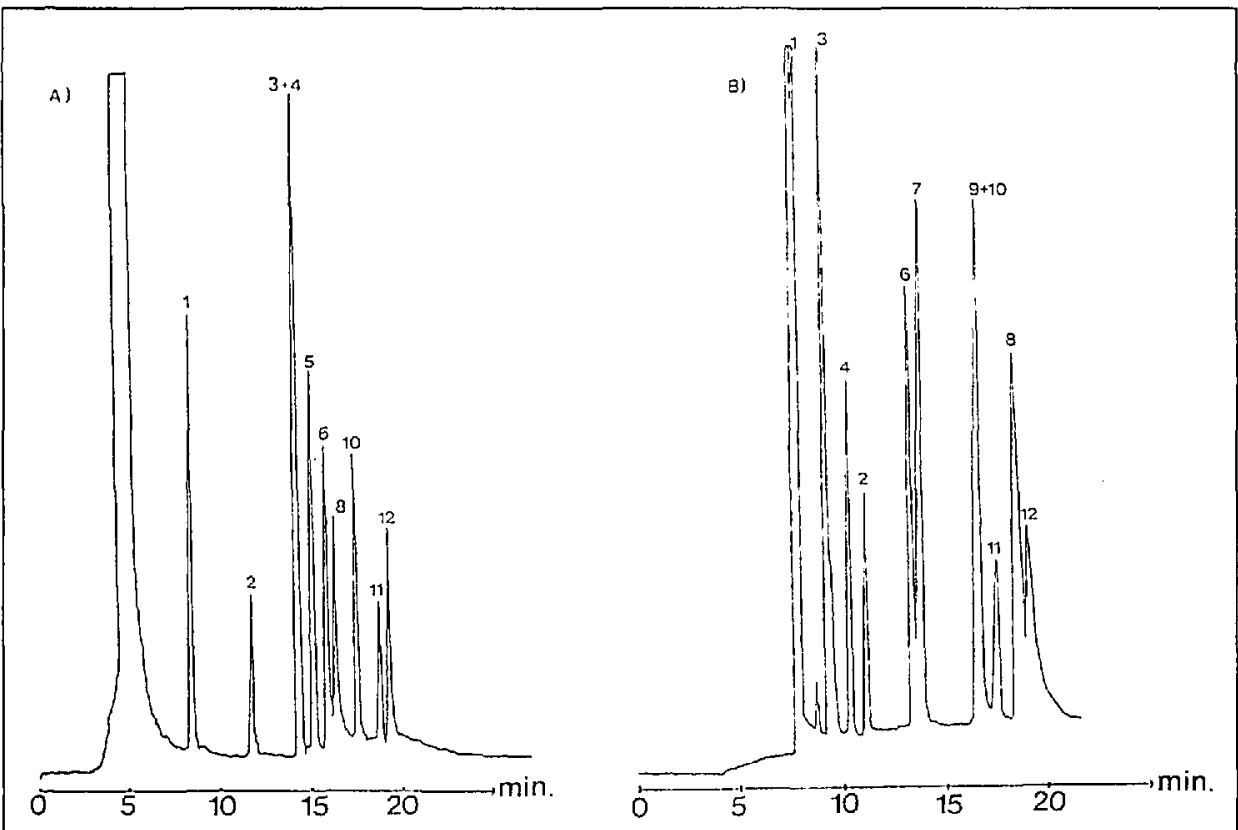

Fig. 2. Capillary SFC Chromatograms A) using DBS column (20 $\mathrm{m} \times 0.1 \mathrm{~mm}$ i.d., film thickness 0.4 $\mu \mathrm{m}), \mathrm{B})$ using DBWAX column $(20 \mathrm{~m} \times 0.1 \mathrm{~mm}$ i.d., film thickness $0.1 \mu \mathrm{m})$. Conditions used: mobile phase $\mathrm{CO}_{2}$. Density programming. FID detection.

Peaks: 1: nicotine, 2: caffeine, 3: methadone, 4: cocaine, 5: imipramine, 6: codeine, 7: diazepam, 8 : morphine, 9: benzoylecgonine, 10: papaverine, 11: narcotine, 12: strychnine.

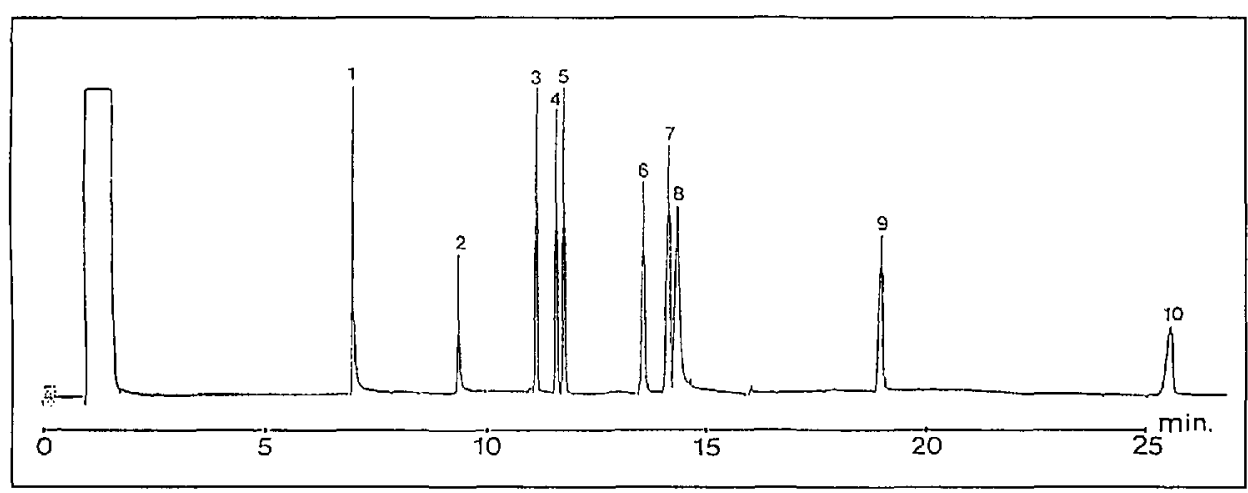

Fig. 3. GC Chromatogram using a SE54 capillary column $(25 \mathrm{~m} \times 0.32 \mathrm{~mm}$ i.d., film thickness 0.53 $\mu \mathrm{m})$. Conditions used: gas carrier He, FID detection. Solutes: 1: nicotine, 2: caffeine, 3: methadone, 4: cocaine, 5: imipramine, 6: codeine, 7: diazepam, 8: morphine, 9: papaverine, 10: strychnine. caine, morphine and diazepam were not separated with the DB5 column. Moreover, the benzoylecgonine, which possesses a $\mathrm{COOH}$ group is coeluted with the solvent and, hence, can not be analyzed without prior derivatization. Therefore, the separation on the polar DBWAX column was investigated. In this case, a fairly good separation of cocaine and methadone was obtained and benzoylecgonine was chromatographed, but it was co-eluted with papaverine. However, the internal standard papaverine can be easily replaced by another compound to prevent the coelution of the latter, and, hence, it would be possible to analyze simultaneously cocaine and its major metabolite, the benzoylecgonine, without any derivatization step. In contrast, GC cannot be used for the simultaneous determination of these two drugs without derivatization owing to the fact that Carbowax column does not withstand temperatures of $200^{\circ}$ and benzoylecgonine is not volatile enough under these conditions.

The $D B 5$ column is more effective, but less selective than $D B W A X$ column showing that the interaction between the analyte, and the stationary phase is stronger in $D B W A X$ column. The solutes were eluted from the $D B 5$ column in the order of their volatility, whereas they were eluted from the DBWAX in the order of polarity. These findings demonstrate that basic drugs can be solubilized in supercritical $\mathrm{CO}_{2}$ without any modifiers and, thus, it may be possible to extract these drugs by SFE. The main problem encountered in SFE is the matrix effect rather than the solubility which can be readily solved.

For quantization and reproducibility of results, addition of an internal standard is a prerequisite. The area-variation coefficients, calculated with an internal standard, are slightly better for the $D B 5$ column and are less than $5 \%$. The detection limits were high, due to the small injection volume $(200 \mathrm{nl})$. With the DBWAX column detection limit for morphine was much lower than $D B 5$ owing to a better resolution with this column. However, the detection limits of other compounds were only slightly better than $D B 5$. In both cases, linear calibration curves were obtained over the range $10-1000 \mathrm{ppm}$ (correlation coefficient methadone $D B 5=0.99990$; $D B W A X=0.9988$; codeine $D B 5=0.9984$; $D B W A X=0.9979$; morphine $D B 5=$ 0.9986; $D B W A X=0.9992$ ).

\section{Comparison with Gas Chromatography}

For comparison purposes, GC analyses were performed. A typical chromatogram obtained using the following temperature conditions: Initial $T=65^{\circ}, 1 \mathrm{~min}$, rate $=30^{\circ} / \mathrm{min}, T=280^{\circ}$ during $6 \mathrm{~min}$, rate 
$=10^{\circ} / \mathrm{min}$, final $T=300^{\circ}$, during $10 \mathrm{~min}$, is shown in Fig. 3.

Comparison of results reported in $\mathrm{Ta}$ ble 3 with those of Tables 1 and 2 reveal that the capacity factors for GC are higher than in SFC. The selectivities are better in GC than in SFC in the instance of separation of all the analytes. Narcotine cannot be determined by GC owing to its high boiling point, whereas benzoylecgonine can be analyzed only if it is derivatized.

As expected, the number of theoretical plates were markedly higher in GC than in SFC. The GC area-variation coefficients were better than that in SFC because of the injection difficulty [1][30]. The detection limits are lower in GC than in SFC. The detection limits are chiefly limited in the SFC due to the difficulties in optimizing the positioning of the restrictor into the FID flame jet and by the small injected volume. To achieve improved sensitivities, methods permitting larger injection volume such as the solvent venting technique must be used [1][28][29]. Regarding the efficiency and reproducibility of the method, SFC in its present state of the art cannot replace GC. However, SFC might be potentially a good alternative for the analysis of non-volatile, thermolabile or acidic solutes.

\subsection{Supercritical Fluid Extraction}

Extraction conditions for recovering basic drugs were determined by batch method prior to applying SFE to complex biological matrix. The extraction procedure used here differed from the conventionally used method in that basic drug solutions were adsorbed on to solid supports prior to extraction. The support acts as the matrix and the extractions in the presence of matrix effects were performed for simulating the biological systems. For simplicity, optimization of extraction conditions was done using morphine. Since morphine is the most polar of the drugs of abuse tested in this study, it would be the most difficult to extract and the optimal conditions found for morphine should, therefore, be applicable to other drugs of interest.

\subsubsection{Choice of the Support for Loading Morphine}

A good support should fullfill the following criteria: it should adsorb morphine and drugs quantitatively, and its breakthrough volume prior to SFE should be reasonnable. Therefore, various silica supports were tested by pumping $10^{-5} \mathrm{M}$ aq. morphine solutions through the extraction cells packed with these supports. The morphine elutant was monitored by measuring the absorbance at $285 \mathrm{~nm}$ using a UV diode array detector.

Table 1. SFC Chromatographic Separation Data for Basic Drugs of Abuse on the DB5 Column $n^{\text {a) }}$

\begin{tabular}{llllll} 
Substances & $k$ & $\alpha$ & $N$ & $C V$ & Det. lim. \\
\hline Nicotine & 0.87 & 1.84 & 16270 & 3.3 & 20 \\
Caffeine & 1.6 & 1.38 & 47709 & 1.9 & 50 \\
Methadone & 2.20 & 1.00 & 55400 & 3.6 & 20 \\
Cocaine & 2.20 & 1.07 & 64250 & 2.0 & 20 \\
Imipramine & 2.33 & 1.06 & 67486 & 2.1 & 20 \\
Codeine & 2.49 & 1.04 & 68786 & 1.8 & 20 \\
Morphine & 2.60 & 1.01 & 36487 & 1.9 & 160 \\
Diazepam & 2.33 & 1.09 & 52229 & n.d. & n.d. \\
Papaverine & 2.87 & 1.08 & 73691 & IS & 50 \\
Narcotine & 3.11 & 1.04 & 85183 & 3.0 & 50 \\
Strychnine & 3.87 & & 103114 & 2.8 & 20 \\
Benzoylecgonine & & COOH function, no peak! & &
\end{tabular}

a) $k^{\prime}=$ Capacity factor; $\alpha=$ selectivity; $N=$ theoretical number of plates, $C V=$ peak-area variation coefficient $(n=6)$; det. lim. = detection limit in ppm; n.d. = not determined; IS = internal standard.

Table 2. SFC Chromatographic Separation Data for Basic Drugs of Abuse on the DBWAX Column $n^{\mathrm{a}}$

$\begin{array}{llllll}\text { Substances } & k^{\prime} & \alpha & N & C V & \text { Det. lim. } \\ \text { Nicotine } & 0.04 & & \text { n.d. } & \text { n.d. } & \text { n.d. } \\ \text { Mehadone } & 0.22 & 5.50 & 23406 & 3.7 & 10 \\ \text { Cocaine } & 0.36 & 1.64 & 26939 & 3.9 & 20 \\ \text { Caffeine } & 0.46 & 1.27 & 27243 & 3.9 & 25 \\ \text { Codeine } & 0.72 & 1.65 & 19086 & 4.6 & 25 \\ \text { Diazepam } & 0.83 & 1.09 & 16108 & 4.1 & 10 \\ \text { Papaverine } & 1.19 & 1.21 & 23242 & 2.6 & \text { n.d. } \\ \text { Benzoylecgonine } & 1.19 & 1.00 & 24132 & 2.8 & 25 \\ \text { Narcotine } & 1.27 & 1.07 & 18654 & 3.3 & \text { IS } \\ \text { Morphine } & 1.38 & 1.09 & 15944 & 3.6 & 50 \\ \text { Strychnine } & 1.46 & 1.06 & 11876 & 4.2 & 50\end{array}$

a) $k^{\prime}=$ Capacity factor; $\alpha=$ selectivity; $N=$ theoretical number of plates; $C V=$ peak-area variation coefficient $(n=6)$; det. lim. = detection limit in ppm; n.d. = not determined; IS = internal standard.

Water was used as the blank and was pumped through the extraction cell and the absorption of the blank at the outlet of the cell was measured at $285 \mathrm{~nm}$ during 2 min. Then, the absorption of morphine solution was measured at $285 \mathrm{~nm}$ in extraction cell by-pass mode for $2 \mathrm{~min}$. Fi- nally, morphine was loaded by switching the valve in the extraction cell mode and the morphine elution was monitored (Fig. 4). The results obtained for loading of six different silica as given in Table 4 show that $C 18$ silica and phenyl silica are the best supports for loading morphine. 
Table 3. Gas Chromatographic Separation Data for Basic Drugs of Abuse on the SE54 Column ${ }^{\mathrm{a}}$ )

\begin{tabular}{llllll} 
Substances & $k^{\prime}$ & $\alpha$ & $N$ & $C V$ & Det. lim. \\
\hline Nicotine & 6.04 & 1.40 & 456960 & 3.5 & 8 \\
Caffeine & 8.42 & 1.21 & 418527 & 2.1 & 20 \\
Methadone & 10.17 & 1.04 & 499475 & 1.5 & 0.2 \\
Cocaine & 10.61 & 1.02 & 487856 & 1.4 & 1 \\
Imipramine & 10.79 & 1.17 & 499454 & 1.5 & 1 \\
Codeine & 12.60 & 1.04 & 297757 & 1.8 & 2 \\
Diazepam & 13.10 & 1.02 & 76200 & 2.0 & 2 \\
Morphine & 13.33 & 1.35 & 318661 & 1.9 & 20 \\
Papeaverine & 17.93 & 1.36 & 490959 & IS & 5 \\
Strychnine & 24.43 & & 204700 & 3.5 & 50 \\
Narcotine & - & - & - & - & - \\
Benzoylecgonine & - & - & - & - & -
\end{tabular}

') $k^{\prime}=$ Capacity factor; $\alpha=$ selectivity; $N=$ theoretical number of plates; $C V$ area $=$ peak area variation coefficient $(n=6)$; det. $\lim .=$ detection limit in ppm; $\mathrm{n} . \mathrm{d} .=$ not determined; IS $=$ internal standard.

Table 4. Preconcentration of $10^{-5} \mathrm{M}$ Aqueous Morphine Solution in $\mathrm{H}_{2} \mathrm{O}$ on Various Silica Phases and Resin ${ }^{\mathrm{a}}$ )

\begin{tabular}{llll}
\hline Silica & Trade-mark & $m / \mathrm{mg}$ & $V P_{\max }$ \\
\hline $\mathrm{CN}$ & Waters & 75 & $4 \mathrm{ml}$ \\
$\mathrm{SiOH}$ & Waters & 100 & $20 \mathrm{ml}$ \\
Diol & Waters & 150 & N.P. \\
Phenyl & Baker & 130 & $>60 \mathrm{ml}$ \\
PRPI & Hamilton & 100 & $60 \mathrm{ml}$ \\
$\mathrm{NH}_{2}$ & Baker & 130 & N.P. \\
C18 & Macherey-Nagel & 130 & $70 \mathrm{ml}$
\end{tabular}

a) $m=$ weight of the support in the cell. $V P_{\max }=$ maximum preconcentration volume prior to breaktrough. N.P. $=$ No preconcentration observed.

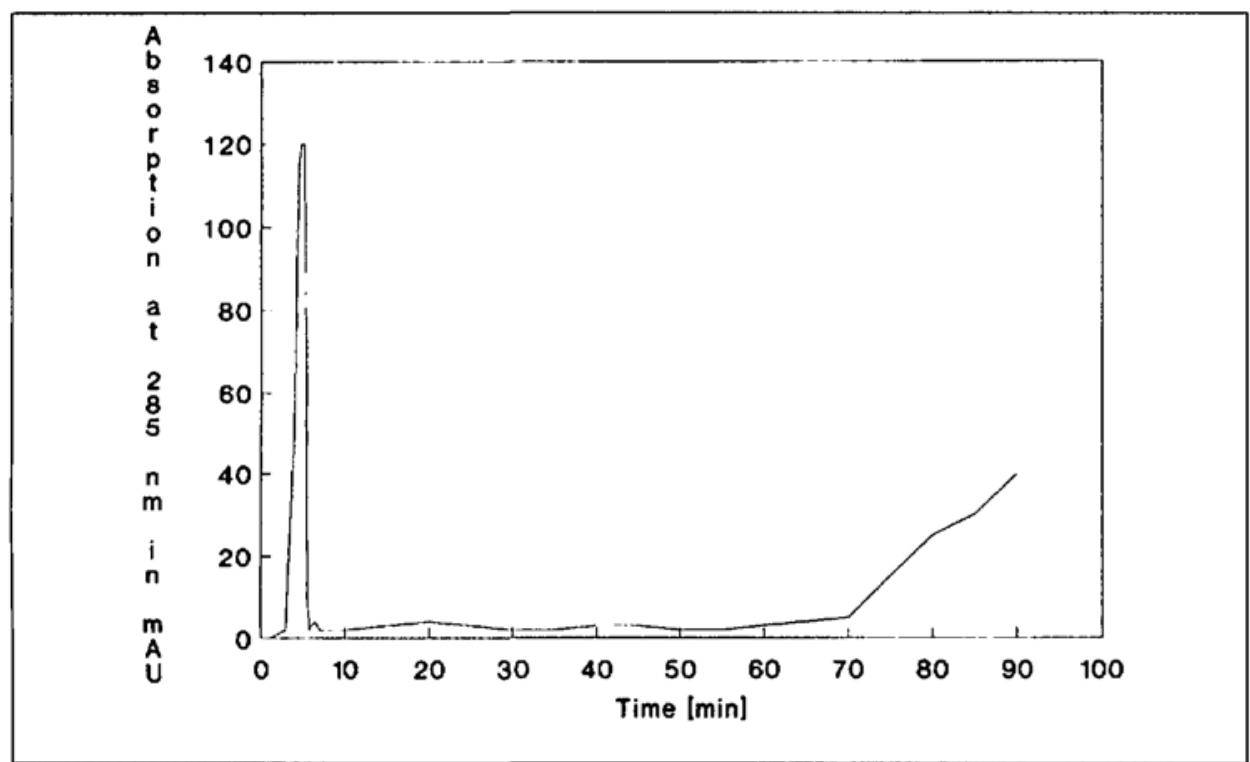

Fig. 4. Monitoring of the morphine-loading step on $\mathrm{C} 18$ silica. Diode array detection $285 \mathrm{~nm}$. Flow rate $1 \mathrm{ml} / \mathrm{min} .0-2 \mathrm{~min}: \mathrm{H}_{2} \mathrm{O}, 2-5 \mathrm{~min}$ : morphine $10^{-5} \mathrm{M}$ aq. solution of morphine by-passing the cell,

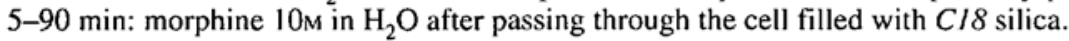

The breaktrough volumes were found to be greater than $60 \mathrm{ml}$ (Fig. 4) and is sufficient for preconcentrating large volume of urine or blood. In subsequent experiments, $\mathrm{C} 18$ silica was chosen as the support for loading and preconcentration.

\subsubsection{Choice of the Extraction Mixture}

Several extraction mixtures were tested to determine the mixture that yields maximum recovery.

For this purpose, $20 \mathrm{ml}$ of $10^{-4} \mathrm{M}$ aq. morphine solution was passed through the extraction cell packed with $\mathrm{C} 18$-bonded silica. Then, $10 \mathrm{ml}$ of $\mathrm{H}_{2} \mathrm{O}$ was passed through the cell for rinsing. The cell was then linked to the SFE system, and the analyte was directly extracted with the supercritical fluid mixture. The morphine thus extracted was collected in $\mathrm{MeOH}$ and evaporated under $\mathrm{N}_{2}$. The residue was then dissolved in $200 \mu \mathrm{l}$ of $\mathrm{MeOH}$ and analyzed by GC (under the same conditions as that used for comparison between capillary SFC and GC). Recoveries of the preconcentrated samples were determined. Preliminary studies with $\mathrm{CO}_{2}$ as extractant indicated that morphine cannot be extracted from $\mathrm{Cl}$-bonded silica. $\mathrm{CO}_{2}+$ $\mathrm{MeOH}$ was also found to be not suitable for extracting morphine, as recoveries were poor. The recoveries increase with increasing amounts of $\mathrm{MeOH}$ in $\mathrm{CO}_{2}$. An extractant mixture containing $20 \% \mathrm{MeOH}$ gave a recovery of $65 \%$ at $30 \mathrm{MPa}$ and elution time of $30 \mathrm{~min}$. Hence, it would be possible to carry out SFE with fractionation. For example, apolar solutes can be eluted with $\mathrm{CO}_{2}$, and this would serve as a clean up step. The presence of more than $10-15 \%$ of the modifier in $\mathrm{CO}_{2}$ causes a change in the supercritical conditions and the extractant mixture is no longer in supercritical state [1]. The poor recoveries or reproductabilities might be due to the fact that the extractant mixture may not be homogeneous and the existence of several phases hampers the elution. To overcome these problems, a ternary mixture $\mathrm{CO}_{2}$ ' $\mathrm{MeOH} / \mathrm{Et}_{3} \mathrm{~N}$ was used, the advantage being that lower proportions of modifier are required for elution. The effect of the composition of the modifier on morphine recoveries are shown in Figs. 5 and 6 (aliquots of elutant were collected after $20,25,30$, and $35 \mathrm{~min}$, concentrated and analyzed by GC). These results show that as the amount of $\mathrm{Et}_{3} \mathrm{~N}$ in the mixture increases, the recovery increases. Note that $5 \%$ of modifier $\left(\mathrm{MeOH}+\mathrm{Et}_{3} \mathrm{~N}\right)$ is not sufficient for extracting morphine with $100 \%$ recovery. $100 \%$ yields were obtained with extractant mixture having the following composition: $90 \% \mathrm{CO}_{2} / 8.5 \%$ $\mathrm{MeOH} / 1.5 \% \mathrm{Et}_{3} \mathrm{~N}$ at $25 \mathrm{MPa}$ with an extraction time of $25 \mathrm{~min}$ and a flow rate 


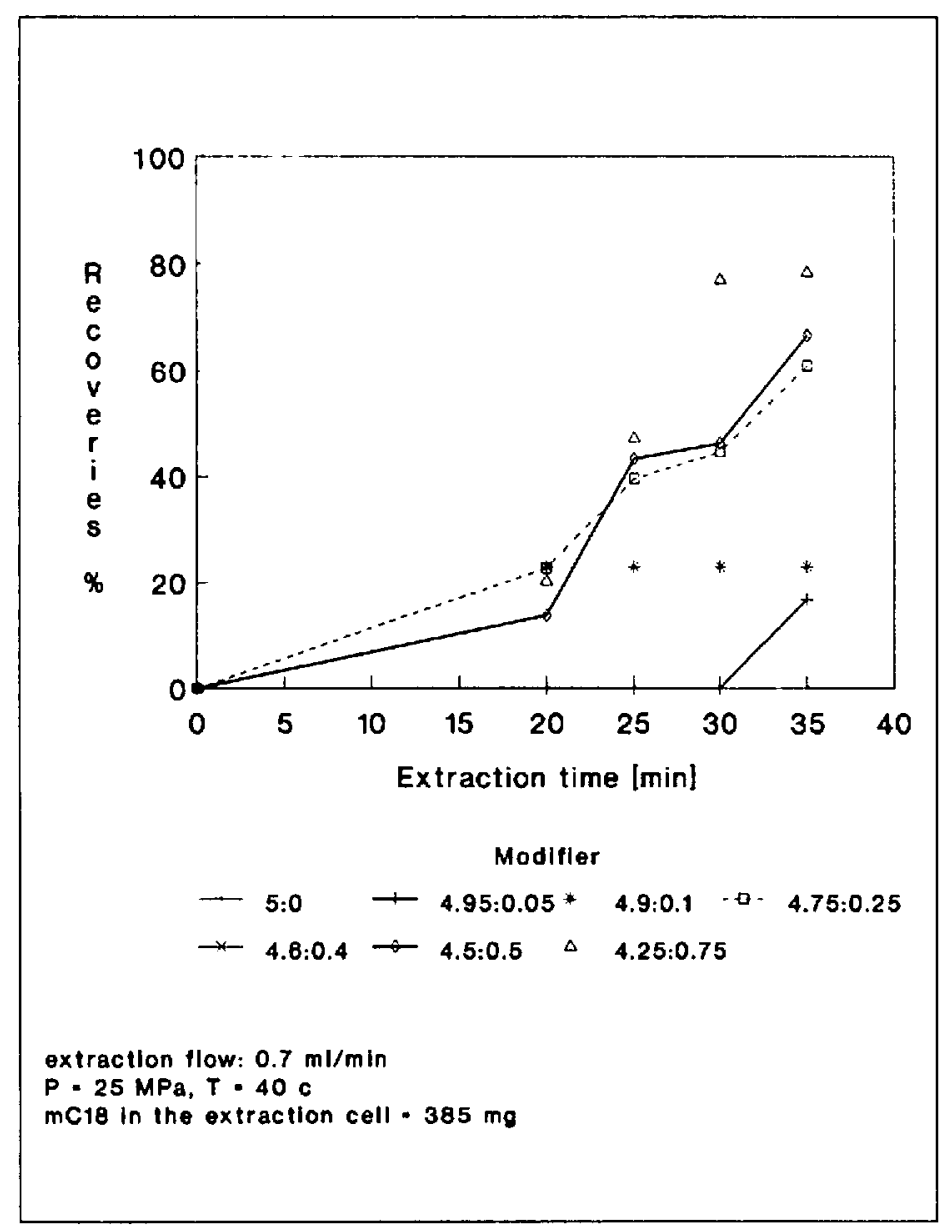

Fig. 5. SFE recoveries of morphine with modifiers concentrations. $\mathrm{MeOH} /$ $\mathrm{Et}_{3} \mathrm{~N}$ percentage $(v / v)$ in the mixture varied keeping $\mathrm{CO}_{2}$ percentage constant (95\%). Conditions used: $P=25 \mathrm{MPa}, T=40^{\circ}$, Extraction flow: 0.7 $\mathrm{ml} / \mathrm{min}$.

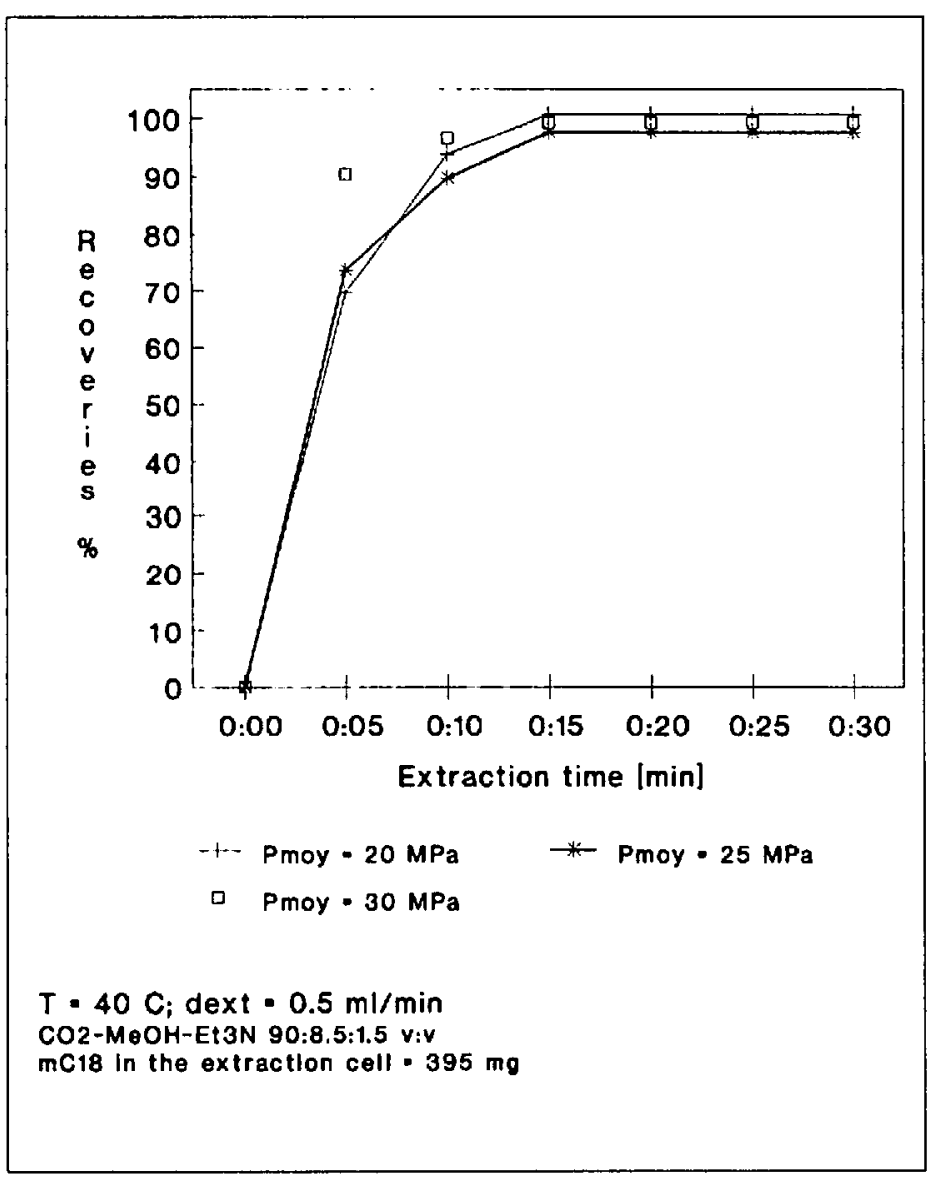

Fig. 7. Effect of $S F E$ pressure on the morphine extraction recoveries from C18 silica. Mobile phase: $\mathrm{CO}_{2} / \mathrm{MeOH} / \mathrm{Et}_{3} \mathrm{~N}$ 90/8.5/1.5 $(v / v), T=40^{\circ}$, Extraction flow rate: $0.5 \mathrm{ml} / \mathrm{min}$.

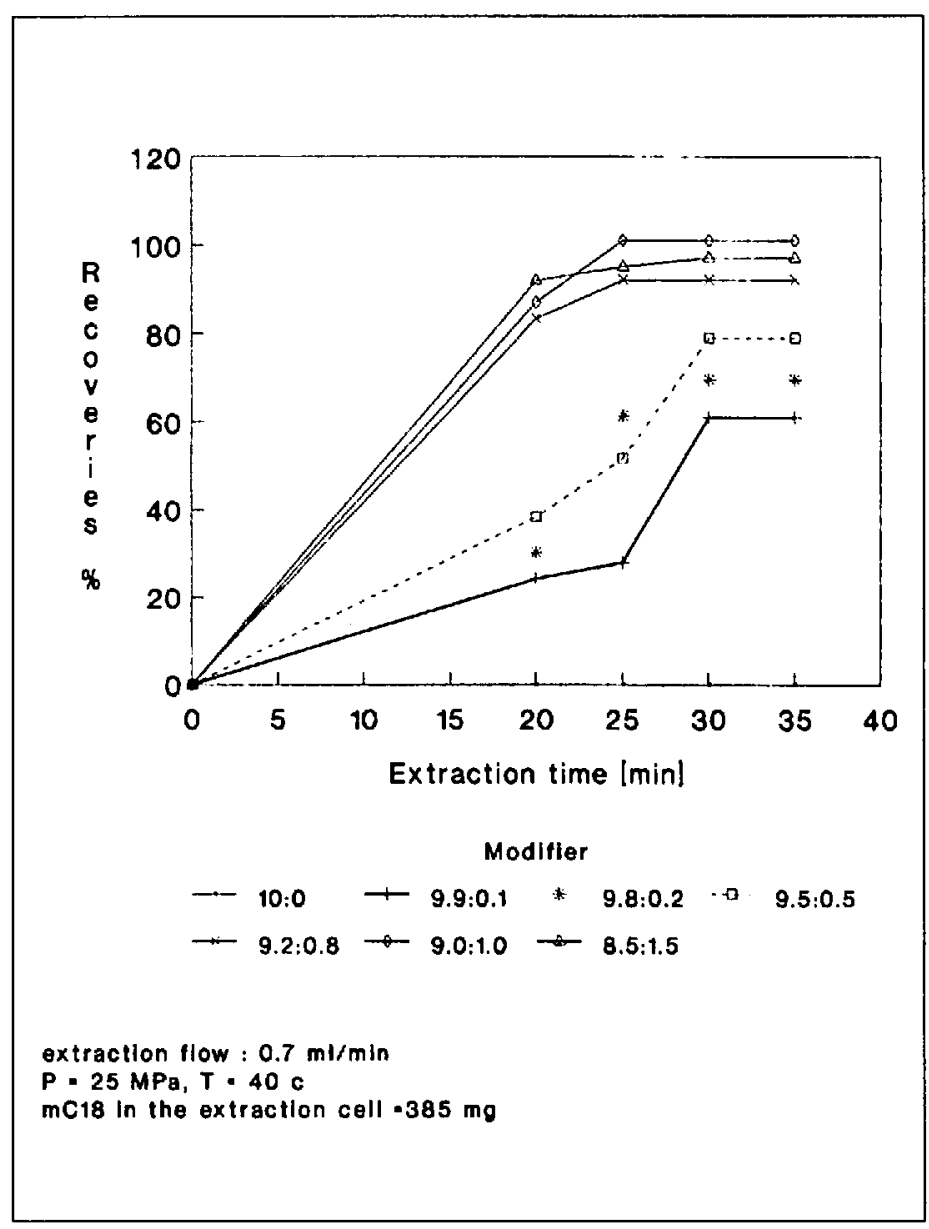

Fig. 6. SFE recoveries of morphine with modifiers concentrations. $\mathrm{MeOH} /$ $\mathrm{Et}_{3} \mathrm{~N}$ percentage $(v / v)$ in the mixture varied keeping $\mathrm{CO}_{2}$ percentage constant $(90 \%)$. Conditions used: $P=25 \mathrm{MPa}, T=40^{\circ}$, Extraction flow: 0.7 $\mathrm{ml} / \mathrm{min}$.

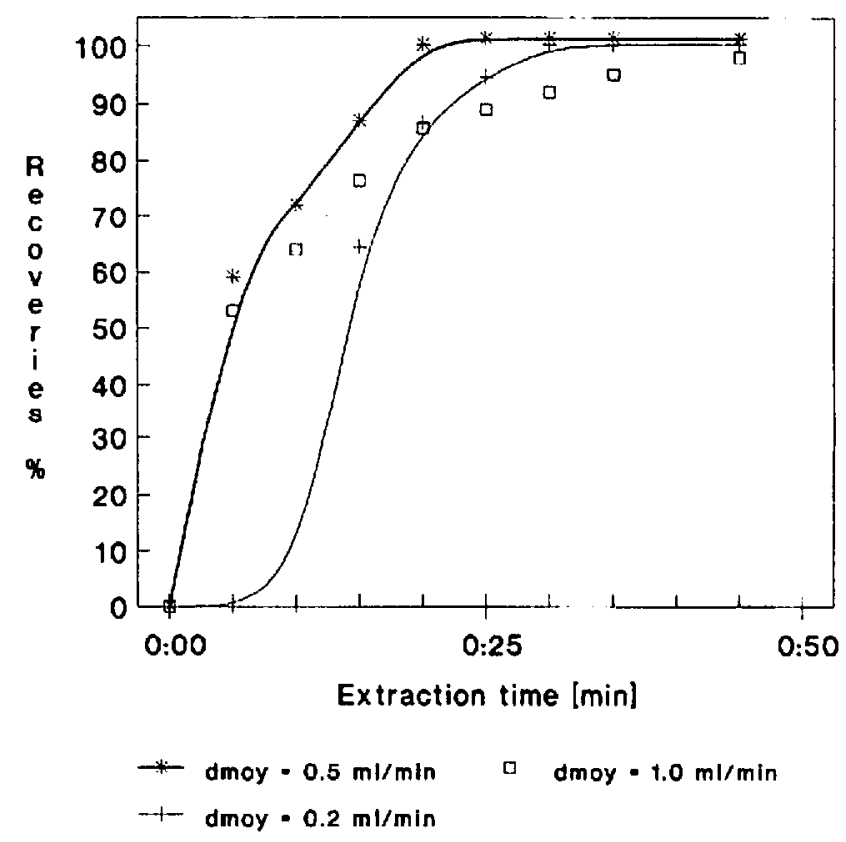

$\mathrm{T}=40 \mathrm{C} ; \mathrm{P}=25 \mathrm{MPa}$

CO2-MeOH-Et3N 90:8.5:1.5 v:v

$\mathrm{mC18}$ in the extraction cell : $389 \mathrm{mg}$

Fig. 8. SFE kinetic profiles of adsorbed morphine on $\mathrm{C} 18$ silica for various extraction flow rate. Conditions used: mobile phase $\mathrm{CO}_{2} / \mathrm{MeOH}^{-} \mathrm{Et}_{3} \mathrm{~N}$ 90:8.5:1.5 (v/v), $P=25 \mathrm{MPa}, T=40^{\circ}$. 
Fig. 9. Variation of the preconcentration volume of morphine on C18 silica for SFE research for the breakthrough volume. Conditions used: mobile phase $\mathrm{CO}_{2} / \mathrm{MeOH} /$ $\mathrm{Et}_{3} \mathrm{~N}$ 90:8.5:1.5 $(v / v) 1$ $141 \quad 148 P=25$ $\mathrm{MPa}, T=40^{\circ}$.

$0.5 \mathrm{ml} / \mathrm{min}$. In subsequent experiments, this mixture was used for extraction of morphine under the SFE conditions.

It must be pointed out that in the absence of $\mathrm{H}_{2} \mathrm{O}$ only $19 \%$ recovery was obtained. $\mathrm{H}_{2} \mathrm{O}$ present in the cell either acts as modifier facilitating the passage of supercritical fluid through the matrix or modifying the interactions between the matrix and the morphine in the same way as those described for cafeine from coffee beans [31].

\subsubsection{Influence of Pressure}

SFE was performed at three different pressures and aliquots of elutant were collected at intervals of $5 \mathrm{~min}$ and analyzed by GC. In all cases, $100 \%$ recoveries were obtained after $20 \mathrm{~min}$ (Fig. 7). Pressure of $25 \mathrm{MPa}$ was chosen in all our experiments due to practical reasons e.g. flow rate is more constant and the restrictor is less plugged.

\subsubsection{Kinetic Extraction Profile}

The influence of extraction flow rate on drug recoveries was examined by collecting elutant every $5 \mathrm{~min}$ at various flow rates and analyzing the morphine by GC. The recovery $v s$. extraction time profiles at various flow rate in Fig. 8 shows that for flow rates greater than or equal to $1 \mathrm{ml} /$ $\mathrm{min}$, the recoveries of morphine decrease showing that extraction kinetics plays an important role in the recovery of morphine. The SFE kinetic profiles at flow rates of $0.5 \mathrm{ml} / \mathrm{min}$ and $0.2 \mathrm{ml} / \mathrm{min}$ are similar except that the curves in the latter case are displaced towards longer extraction time. These findings emphasize the important role played by the restrictor in controlling precisely the flow rate at constant pressure. The novel restrictor system used in this work allows precise control of flow rates at constant pressure. The optimal flow rate for quantitative recovery is in the range $0.4-0.7 \mathrm{ml} / \mathrm{min}$.

\subsubsection{Reproducibility, Calibration and} Maximum Breakthrough Volume

The reproducibility of 12 replicate measurements was $2 \%$ (within the limits of error of the GC method, and the mean recovery was $99.2 \%$. The detection limit was found to be $30 \mathrm{ppm}$ and is comparable with $\mathrm{GC}(20 \mathrm{ppm}) .20 \mathrm{ml}$ of aq. morphine solutions having various concentrations were preconcentrated and extracted by SFE. Residues left after evaporation of solvent were dissolved in $50 \mu \mathrm{l}$ of $\mathrm{MeOH}$ and morphine was analyzed by GC. A plot of surface area vs. concentration in Fig. 9, shows excellent linearity $(r=0.9998)$. It should be noted that it was difficult to dissolve the residue in less than $50 \mu \mathrm{l}$ of $\mathrm{MeOH}$, but it is possible to preconcentrate a larger volume of solution. Although volumes greater than $150 \mathrm{ml}$ yielded linear relationship with high concentration factors, but it was time-consuming. However, volumes of $50 \mathrm{ml}$ can be preconcentrated within a reasonable time and a preconcentration factor of 1000 can be achieved.

\subsubsection{Supercritical Fluid Extraction of Other Basic Drugs}

The SFE recoveries for other basic drugs were determined under the same conditions as those for morphine (extractant mixture: $\mathrm{CO}_{2} / \mathrm{MeOH} / \mathrm{Et}_{3} \mathrm{~N}$ 90:8.5:1.5 $v / v ; 25 \mathrm{MPa} ; 0,5 \mathrm{ml} / \mathrm{min}$, extraction time: $25 \mathrm{~min})$. The mean recoveries and the variation coefficients (for $n=5$ ) for methadone, cocaine, codeine, and papaverine are given for Table 5. As can be seen, the results are good indicators that this method of extraction is suitable for the screening of basic drugs of abuse other than morphine.

\section{Conclusion}

The results of SFC studies reported here have demonstrated that basic drugs of abuse dissolve in pure $\mathrm{CO}_{2}$ without modifier. SFC can be used for analysis of basic drugs, but its advantage over GC is at the present time not significant.

Morphine recoveries with SFE were excellent ( $100 \%$ yield), the extraction time being $25 \mathrm{~min}$. SFE studies on morphine revealed that in addition to solubility paramaters, the effect of nature of the matrix has to be taken into account for determining the optimal conditions. Hence optimal conditions of SFE must be determined for a given matrix. The SFE behavior of methadone, cocaine, codeine, and papaverine were similar to that of morphine. The SFE
Table 5. SFE Recoveries and Area-Variation Coefficients of Basic Drugs Other Than Morphine

\begin{tabular}{lll} 
Compound & Yield $[\%]$ & $C V(N=5)$ \\
\hline Methadone & 92 & 3.1 \\
Cocaine & 101 & 2.5 \\
Codeine & 98.2 & 1.9 \\
Papaverine & 100.1 & 2.4
\end{tabular}


method described in this paper allows large volumes of sample to be preconcentrated and high concentration factors can be achieved. This is important in trace analysis. This method would be applicable to the analysis of drugs of abuse in physiological fluids such as urine and blood. Although extraction of drugs of abuse from urine and blood is well established no attempts have yet been made to analyze these on-line by coupling SFE to chromatographic techniques. Off-line analysis of urine, blood, liver, kidney, and hairs is underway.

We warmly thank $M$. Rupper Haering for technical assistance and the Swiss National Scientific Research Foundation for financial support.

Received: January 20, 1992

[1] M.L. Lee, K.E. Markides, 'Analytical Supercritical Fluid Chromatography and Extraction', Eds.M.L.Lee amd K.E. Markides, Chromatography Conferences Inc., Provo, 1990, p. 313.
[2] S.B. Hawthorne, Anal. Chem. 1990, 62 , $633 \mathrm{~A}$.

[3] J.W. King, J. Chromatogr. Sci. 1989, 27, 355 .

[4] J.L. Veuthey, M. Caude, R. Rosset, Analusis $1990,18,103$.

[5] R.W. Vannoort, J.P. Chervet, H. Lingeman, G.J. Dejong, U.A. Brinkman, J. Chromatogr. 1990, 505, 45.

[6] K.G. Furton and J. Rein, Anal. Chim. Acta 1990, 237, 99.

[7] J.D. Pinkston, T.E. Delaney, D.J. Bowling, T.L. Chester, High Resolut. Chromatogr.1991, 14, 401 .

[8] E. Stahl, J. Chromatogr. 1977, 142, 15.

[9] S.M. Fields, K. Grolimund, J. High Resolut. Chromatogr. 1988, 727, 11

[10] F. David, P. Sandra, J. High Resolut. Chromatogr. 1988, 897, 11

[11] O. Gyllenhaal, J. Vessman, J. Chromatogr. $1990,516,415$.

[12] T.L. Chester.D.P. Innis, J. High Resolut. Chromatogr. 1986, 9, 178

[13] J.L. Janicot, M. Caude, R. Rosset, J. Chromatogr. 1988, 437, 351 .

[14] T.L. Chester, D.P. Innis, J. High Resolut Chromatogr. 1986, 9, 561.

[15] R.M. Smith, M. Sanagi, J. Chromatogr. $1990,505,147$.

[16] J.L. Veuthey, W. Haerdi, J. Chromatogr. $1990,515,385$.

[17] R.M. Smith, M. Sanagi, J. Chromatogr. $1989,483,51$
[18] R.M. Smith, M. Sanagi, J. Chromatogr. 1989, 48I, 63.

19] D.W. Roberts, I.D. Wilson, Methodol. Surv. Biochem. Anal. 1990, 257

[20] W.Steuer, J. Baumann, F. Erni, J. Chromatogr. 1990, 500, 469.

[21] D.W. Later, B.E. Richter, D.E. Knowles, M.R. Andersen, J. Chromatogr. Sci. 1986, 24, 249.

[22] G.A. Mackay, G.D. Reed, J. High Resolut. Chromatogr. 1991, 14, 537.

[23] J.M. Mulcahey, L.T. Taylor, J. High Resolut. Chromatogr. 1990, 13, 393.

[24] S.H.Y. Wong, Clin. Chem. 1989, 35, 1293.

[25] R.L. Eatherton, M.A. Morissey, H.H. Hill, Anal. Chem. 1988, 60, 2240.

[26] L. Karlsson, L. Mathiasson, J. Akesson, J. Jonsson, J. Chromatogr. 1991, 557, 99.

[27] J.L. Janicot, M. Caude, R. Rosset, J.L. Veuthey, J. Chromatogr. 1990, 505, 247.

[28] B.E. Richter, D.E. Knowles, M.R. Andersen, N.L. Porter, E.R. Campbel, J. High Resolut. Chromatogr. 1988, II, 29.

[29] M.L. Lee, B. Xu, E.C. Huang, N.M. Djordjevic, H.C.K. Chang, K.E. Markides $J$. Microcol, Sep. 1989, $1,7$.

[30] B.E. Berg, T. Greibrokk, J. High Resolut Chromatogr. 1989, 12, 322

[31] K. Sugiyama, M. Saito, T. Hondo, M. Senda, J. Chromatogr. 1985, 332, 107.
Chimia 46 (1992) 148-151

(c) Schweiz Chemiker-Verband; ISSN 0009-4293

\section{Photophysical Behavior of Malachite Green in Solid and Liquid Media}

\section{Renata Reisfeld ${ }^{a}$ ), Valery Chernyak $^{a}$ ), and Christian K. Jørgensen $\left.{ }^{b}\right)^{*}$}

Abstract. Malachite Green (MG) incorporated in glass appears in four forms. In acidic glasses, yellow $\mathrm{H}(\mathrm{MG})^{2+}$ protonated dications; the green monocation $\mathrm{MG}^{+}$in $\mathrm{H}_{2} \mathrm{O}$ at $\mathrm{pH} 4$ to 6 ; the colorless carbinol base $\mathrm{HO}(\mathrm{MG})$ at higher $\mathrm{pH}$; and a new purple species in certain glasses prepared by mineral acid catalysis. Uniquely high luminescence yields indicate formation of chemical bonds between $\mathrm{MG}^{+}$and the silicate groups, suggesting Lewis-acid behavior of three-coordinated carbon. Novel cascade emission is observed from the three first excited singlets $S_{1}, S_{2}$, and $S_{3}$. In sol-gel glasses, green $\mathrm{MG}^{+}$bleaches reversibly under illumination

\section{Introduction}

The triphenylmethane colorant Malachite Green (MG) incorporated in sol-gel glasses or other polymers recently attracted attention due to its unusual optical properties, manifested also on a very shorttime scale [1]

A systematic study of absorption and in particular the novel emission spectra showing high luminescence yields as a function of preparative procedure [2][3] give the motivation to attempt a rationalization of the unusual spectroscopy based on a general distinction between the coordination numbers $N=3$ and $N=4$ of carbon in aromatic molecules and ions.

It is especially appealing to study the monocationic form of Malachite Green $\mathrm{MG}^{+}\left(\left[\mathrm{PhC}\left(\mathrm{C}_{6} \mathrm{H}_{4} \mathrm{NMe}_{2}\right)_{3}\right]^{+}\right)$and its proto- nated form in gel glasses [3], in which the luminescent ions are situated in a small isolated cavity. Recently, a gel glass composed of $\mathrm{SiO}_{2}$ and $\mathrm{ZrO}_{2}$ [1] containing $\mathrm{MG}^{+}$was shown to become reversibly transparent to incident energies of microjoules with a recovery time of picoseconds.

In (MG) the colorless form is attributed here to the four-coordinated C-atom in the carbinol $\mathrm{HO}(\mathrm{MG})$ and the colored forms to three-coordinated $\mathrm{C}$-atom in green $\mathrm{MG}^{+}$and in the yellow protonated dication $\mathrm{H}(\mathrm{MG})^{2+}$. Our suggestions are based on the following consideration:

The most frequent coordination number of non-aromatic $\mathrm{C}$-atom is 4 . Planar aliphatic compounds with $N=3$ such as formate $\mathrm{HCO}_{2}^{-}$, aqueous carbonic acid $(\mathrm{HO})_{2} \mathrm{CO}$ and bicarbonate $\mathrm{HOCO}_{2}^{-}$do not usually absorb in the visible or near UV.

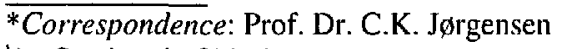

b) Section de Chimie

Université de Genève

30, quai Ernest-Ansermet

$\mathrm{CH}-12$ ll Genève 4

a) Prof. Dr. R.Reisfeld (Enrique Berman Professor of Solar Energy)

Dr. V. Chernyak

Department of Inorganic Chemistry

The Hebrew University

91904 Jerusalem, Israel 